\title{
PATHOLOGY/BIOLOGY
}

\author{
Leigh Hlavaty, ${ }^{1,2}$ M.D.; Jeffery Amley, ${ }^{3}$ B.S.; Kelly Root, ${ }^{1,2}$ B.F.A.; Sarah Avedschmidt ${ }^{4}$ M.D.; Andrea \\ Jaworski, ${ }^{1}$ B.S.; and LokMan Sung, ${ }^{1,2}$ M.D.
}

\section{The Difficulties in Assessing Wounds Created by .410 Bore Ammunition and Weapons}

\begin{abstract}
When interpreting firearm injuries, the distinction between gunshot wounds and shotgun wounds is important, and separation of these categories is typically straightforward. However, .410 bore firearms can make the classification difficult. Shotguns and revolvers that can fire the same .410 bore ammunition are readily available. This study investigates the soot and gunpowder deposits and pellet patterning of these two types of weapons using cartridges specially designed for .410 bore revolvers and standard birdshot pellet ammunition. For both ammunition types, the revolver had more prompt pellet dispersion and positive detection of gunpowder at greater distances compared to the shotgun. Additionally, . 410 bore slugs are of similar caliber to many common bullets. In comparing the .410 bore slugs to equivalent bullets, some morphologic differences may be imparted on the skin by the slugs, but the greatest insight into the weapon remained with the retained projectiles.
\end{abstract}

KEYWORDS: forensic science, forensic pathology, .410 bore, shotgun, revolver, pistol

One of the main objectives for the forensic examination of a body is accurate diagnosis of the cause of death. When examining deaths due to firearms, the forensic pathologist must distinguish gunshot wounds from shotgun wounds because this has important implications for the investigation and the accurate certification of death. A shotgun wound or injury created by a projectile(s) fired from a shotgun typically has well-defined morphologic differences from a gunshot wound or injury created by a projectile fired from a rifle or handgun. Knowledge and experience with these types of firearms and the wounds they create make the distinction between the wounds created by shotguns and rifles or handguns relatively straightforward. These distinguishing features have been amply covered elsewhere in entire texts devoted to the topic (1).

The .410 bore cartridge is the smallest, centerfire, shotgun shell that is commonly available and was originally designed to be fired through a .410 bore shotgun. This .410 shotshell also has unique features that impact the wounds they create. Similar to other conventional shotgun cartridges, the .410 shotshell can be loaded with birdshot pellets, buckshot pellets, or slugs. When fired through a shotgun, a .410 bore cartridge loaded with either birdshot or buckshot creates pellet injuries that are easily

\footnotetext{
${ }^{1}$ Wayne County Medical Examiner's Office, 1300 E. Warren Avenue, Detroit, MI.

${ }^{2}$ Department of Pathology, University of Michigan, 1301 Catherine Street, Ann Arbor, MI.

${ }^{3}$ Firearms and Toolmarks Identification Unit, Michigan State Police Forensic Laboratory, Lansing, MI

${ }^{4}$ Sacramento County Coroner's Office, 4800 Broadway Avenue, Sacramento, CA.

Corresponding author: LokMan Sung, M.D. E-mail: 1sung@waynecounty.com Received 10 May 2019; and in revised form 28 June 2019; accepted 14 Aug 2019.
}

identified as shotgun wounds. However, due to the comparable dimensions of the .410 bore slug with multiple common handgun calibers and depending on if the projectile is recovered, the wounds created by these projectiles could have similar features that blur the distinction between shotgun and gunshot wounds.

An added complexity to the proper classification of these wounds is that certain handguns and .410 bore shotguns can chamber the exact same shotshell without any modification of the firearm. To our knowledge, no study has examined the differences in the cutaneous wounds from .410 shotshells fired from a smooth-bored shotgun and a rifled-barreled handgun. We undertook a study to examine the differences in the cutaneous wounds created by .410 shotshells fired from a .410 bore shotgun and a .410 bore revolver at predetermined distances. The .410 bore cartridge loadings included standard birdshot and specialty ammunition designed for .410 bore revolvers. We also examined the differences in the cutaneous wounds created by .410 bore slugs fired from both the shotgun and the revolver and those created from similar-sized handgun calibers at a predetermined distance.

\section{Materials and Methods}

This study was conducted at the Forensic Crime Laboratory in the Detroit Public Safety Headquarters building in cooperation with the Michigan State Police. A Detective Lieutenant for the Michigan State Police, who currently serves as the supervisor of the Firearms and Toolmarks Identification Unit with 23 years law enforcement experience and 13 years forensic science experience, oversaw firearm safety measures and fired all the rounds.

The .410 bore firearms selected for comparison were the Smith \& Wesson ${ }^{\circledR}$ Governor $^{\mathrm{TM}}$ revolver with a $23 / 4$ inch $(7.0 \mathrm{~cm})$ barrel and the Winchester ${ }^{\circledR} 9410$ Packer $^{\mathrm{TM}}$ shotgun having a 20 inch $(50.8 \mathrm{~cm})$ barrel fitted with an improved cylinder choke tube for 
minimal bore constriction. The features of the Smith \& Wesson ${ }^{\circledR}$ Governor $^{\mathrm{TM}}$ revolver have been previously reported and included its ability to chamber both $21 / 2$ inch $(6.35 \mathrm{~cm}) .410$ shotshells and .45 caliber bullets (2). Porcine substrates were used as tissue targets as previous research groups have shown that porcine skin shares many properties with human skin $(3,4)$. Porcine abdominal segments provided broad areas of skin for distinguishing wounding patterns of the .410 bore revolver and shotgun. For longer distances where the wound pattern exceeded the size of the abdominal wall segments, larger rosin paper witness panels were used.

The $2 \frac{1}{2}$ inch Winchester ${ }^{\circledR}$ PDX $1^{\circledR} 410$ Defender $^{\mathrm{TM}}$ was selected for this study, and its features have been previously reported (5). This shotshell was designed to utilize the rifling within the barrel of revolvers like the Smith \& Wesson ${ }^{\circledR}$ Governor $^{\mathrm{TM}}$ and contains three copper plated defensive discs along with $12 \mathrm{BB}$ shot within a wad. The discs are intended to engage the rifling within the barrel for stabilization and can strike the skin in a single location or three depending on the distance traveled while the BB shot disperse.

The target stand used throughout the experiment consisted of a wood-framed benchtop supported by sawhorses. Plywood sheeting was attached to the benchtop to provide sufficient integrity to fasten the porcine abdominal wall segments and rosin paper witness panels (Fig. 1). With the abdominal wall segments and rosin paper affixed as targets, the Smith \& Wesson ${ }^{\circledR}$ Governor $^{\mathrm{TM}}$ revolver and the Winchester ${ }^{\circledR} 9410$ Packer $^{\mathrm{TM}}$ shotgun were loaded with the Winchester ${ }^{\circledR}{\text { PDX } 1{ }^{\circledR}}^{\circledR} 410$ Defender $^{\mathrm{TM}}$ and discharged at six designated muzzle-to-target distances: contact range, 1 foot $(30.5 \mathrm{~cm}), 2$ feet $(61 \mathrm{~cm}), 3$ feet $(91.4 \mathrm{~cm}), 6$ feet $(1.8 \mathrm{~m})$, and 9 feet $(2.7 \mathrm{~m})$. Both .410 bore weapons were then loaded with Remington ${ }^{\circledR}$ American Clay \& Field ${ }^{\mathrm{TM}} \# 8$ birdshot and shot at the six designated distances as well as 15 feet $(4.6 \mathrm{~cm})$ and 30 feet $(9.1 \mathrm{~m})$. To confirm

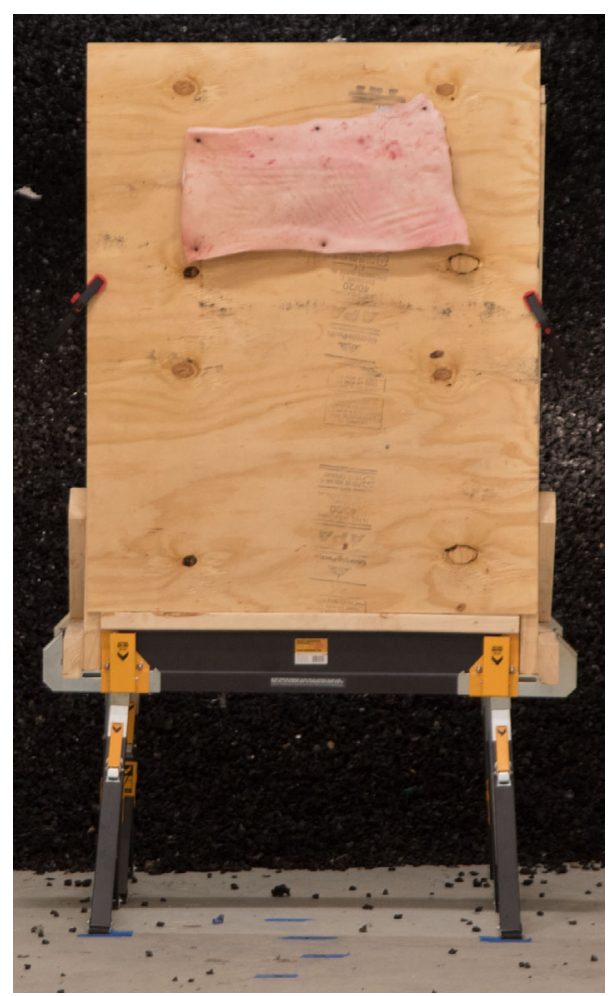

FIG. 1-Target stand supporting abdominal wall segment. [Color figure can be viewed at wileyonlinelibrary.com] reproducible results, five shots were fired from each weapon at each distance for both the .410 shotshell and the \#8 birdshot.

The target stand was then modified by removing the plywood sheeting and concrete masonry units were placed on the benchtop. This allowed insertion of the hock and shank of a porcine leg into the central cavities of the masonry units for vertical orientation of the leg (Fig. 2, the masonry units were painted black to increase their contrast to the porcine legs) The integrity of the underlying muscular support in the porcine legs allowed comparison with entrance wounds produced by .410 bore Foster slugs (Remington ${ }^{\circledR}$ Slugger ${ }^{\circledR}$ rifled slugs) fired from the .410 bore revolver and from the shotgun to those entrance wounds created by similar-caliber jacketed bullets fired from semi-automatic pistols. The semi-automatic pistols discharging these projectiles were the Smith \& Wesson ${ }^{\circledR}$ SW40V ${ }^{\mathrm{TM}}$ with a 4 inch $(10.16 \mathrm{~cm})$ barrel firing the Federal Premium ${ }^{\circledR}$ Personal Defense ${ }^{\circledR}$ HST ammunition in .40 Smith and Wesson (.40 SW), the Smith \& Wesson ${ }^{\circledR} 1006$ with a 5 inch $(12.7 \mathrm{~cm})$ barrel firing the Remington ${ }^{\circledR}$ jacketed hollow point (HP) in $10 \mathrm{~mm}$, and the Smith \& Wesson ${ }^{\circledR} 4516$ with a $3 \frac{3}{4}$ inch $(9.5 \mathrm{~cm})$ barrel firing the Federal Premium $^{\circledR}$ Personal Defense ${ }^{\circledR}$ HST ammunition in .45 Automatic Colt Pistol (.45 ACP). All projectiles fired at the legs were at a distance of 15 feet $(4.6 \mathrm{~m})$, and five shots were fired from each weapon. The wound tracks ended within the leg with the exception of the $10 \mathrm{~mm} \mathrm{HP}$ round that exited the leg, and all other projectiles were recovered from the soft tissue.

\section{Results}

\section{PDX-1 Entrance Wounds}

Table 1 displays the average dimensions of the entrance wounds and/or BB pellet spread diameters, the presence or absence of gunpowder, and wad or wad imprints from discharging the Winchester ${ }^{\circledR}$ PDX $1^{\circledR} 410$ Defender ${ }^{\mathrm{TM}}$ through the Smith \& Wesson ${ }^{\circledR}$ Governor $^{\mathrm{TM}}$ revolver and Winchester ${ }^{\circledR} 9410$ Pack$\mathrm{er}^{\mathrm{TM}}$ shotgun at contact, $1 \mathrm{ft}(30.5 \mathrm{~cm}), 2 \mathrm{ft}(61 \mathrm{~cm}), 3 \mathrm{ft}$ $(91.4 \mathrm{~cm}), 6 \mathrm{ft}(1.8 \mathrm{~m})$, and $9 \mathrm{ft}(2.7 \mathrm{~m})$.

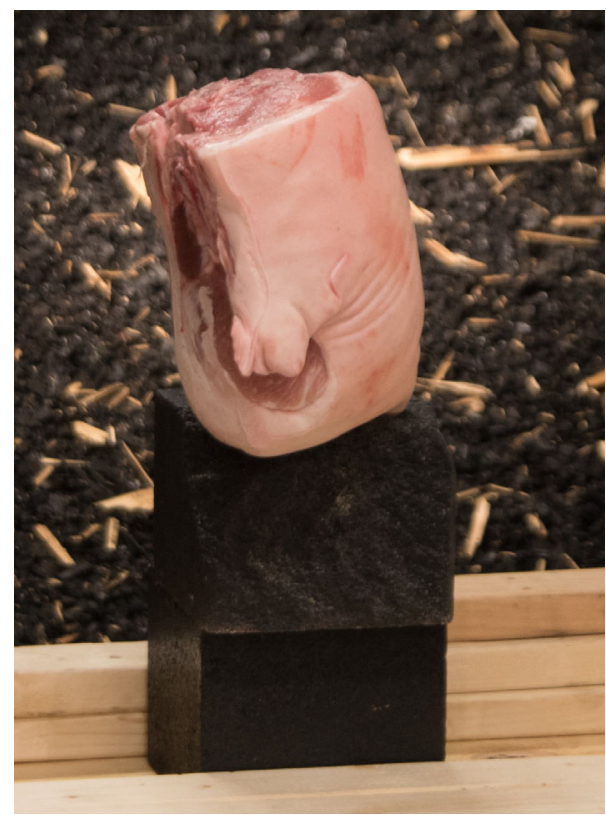

FIG. 2-Concrete masonry units supporting porcine leg. [Color figure can be viewed at wileyonlinelibrary.com] 
TABLE 1-Winchester ${ }^{\circledR}$ PDXI $^{\circledR} 410$ Defender $^{\text {TM }}$ pellet distribution

\begin{tabular}{|c|c|c|c|c|c|c|}
\hline Weapon & Distance & Pellet Spread Diameter & Wound Appearance & Soot & Gunpowder & Wad or Wad Imprint \\
\hline \multirow[t]{6}{*}{9410 Shotgun } & Contact & $0.4 \mathrm{in} / 1.1 \mathrm{~cm}$ & Muzzle imprint & - & - & - \\
\hline & $1 \mathrm{ft} / 30.5 \mathrm{~cm}$ & $0.5 \mathrm{in} / 1.2 \mathrm{~cm}$ & Single hole & + & Fine & - \\
\hline & $2 \mathrm{ft} / 61 \mathrm{~cm}$ & $0.4 \mathrm{in} / 1.1 \mathrm{~cm}$ & Single hole & - & Fine & + \\
\hline & $3 \mathrm{ft} / 91.4 \mathrm{~cm}$ & $0.4 \mathrm{in} / 1.1 \mathrm{~cm}$ & Single hole & - & Fine & + \\
\hline & $6 \mathrm{ft} / 1.8 \mathrm{~m}$ & $0.4 \mathrm{in} / 1.1 \mathrm{~cm}$ & Single hole & - & Rare & + \\
\hline & $9 \mathrm{ft} / 2.7 \mathrm{~m}$ & $0.8 \mathrm{in} / 2.0 \mathrm{~cm}$ & Satellite wounds & - & - & + \\
\hline \multirow[t]{6}{*}{ Governor Revolver } & Contact & $0.5 \mathrm{in} / 1.2 \mathrm{~cm}$ & Muzzle imprint & - & + & - \\
\hline & $1 \mathrm{ft} / 30.5 \mathrm{~cm}$ & $0.6 \mathrm{in} / 1.5 \mathrm{~cm}$ & Single hole & - & Dense & - \\
\hline & $2 \mathrm{ft} / 61 \mathrm{~cm}$ & $1.3 \mathrm{in} / 3.2 \mathrm{~cm}$ & Satellite wounds & - & Dense & + \\
\hline & $3 \mathrm{ft} / 91.4 \mathrm{~cm}$ & $1.9 \mathrm{in} / 4.7 \mathrm{~cm}$ & Dispersed pellets & - & Dense & + \\
\hline & $6 \mathrm{ft} / 1.8 \mathrm{~m}$ & $2.6 \mathrm{in} / 6.6 \mathrm{~cm}$ & Dispersed pellets & - & Fine & $+1-$ \\
\hline & $9 \mathrm{ft} / 2.7 \mathrm{~m}$ & $5.1 \mathrm{in} / 13.1 \mathrm{~cm}$ & Disc separation & - & - & - \\
\hline
\end{tabular}

\section{Contact}

Both revolver and shotgun wounds had faint muzzle imprints on contact, but the shotgun exhibited greater definition of the muzzle. In contrast, the revolver consistently displayed gunpowder at the 12 o'clock position and lacerations radiating from the contact entrance wound, likely originating from a less tight seal due to the front sight post (Fig. 3a).

\section{One Foot $(30.5 \mathrm{~cm})$}

At 1 foot $(30.5 \mathrm{~cm})$, the shotgun wound had soot on the wound edges and surrounding skin and finely and widely dispersed gunpowder (Fig. 3b). The revolver wound was absent of soot but did have evenly dense gunpowder on the surrounding skin. As with the contact wound, the revolver wound showed few radiating lacerations.

\section{Two Feet $(61 \mathrm{~cm})$}

At two feet $(61 \mathrm{~cm})$, the shotgun wounds were atypical circular defects with imprints from the wad or had the wad embedded within the skin. The revolver wounds also had atypical features from wad imprints but showed surrounding satellite wounds from the BBs beginning to spread from the central aggregate (Fig. $3 c$ ). Both weapons showed gunpowder on the surrounding
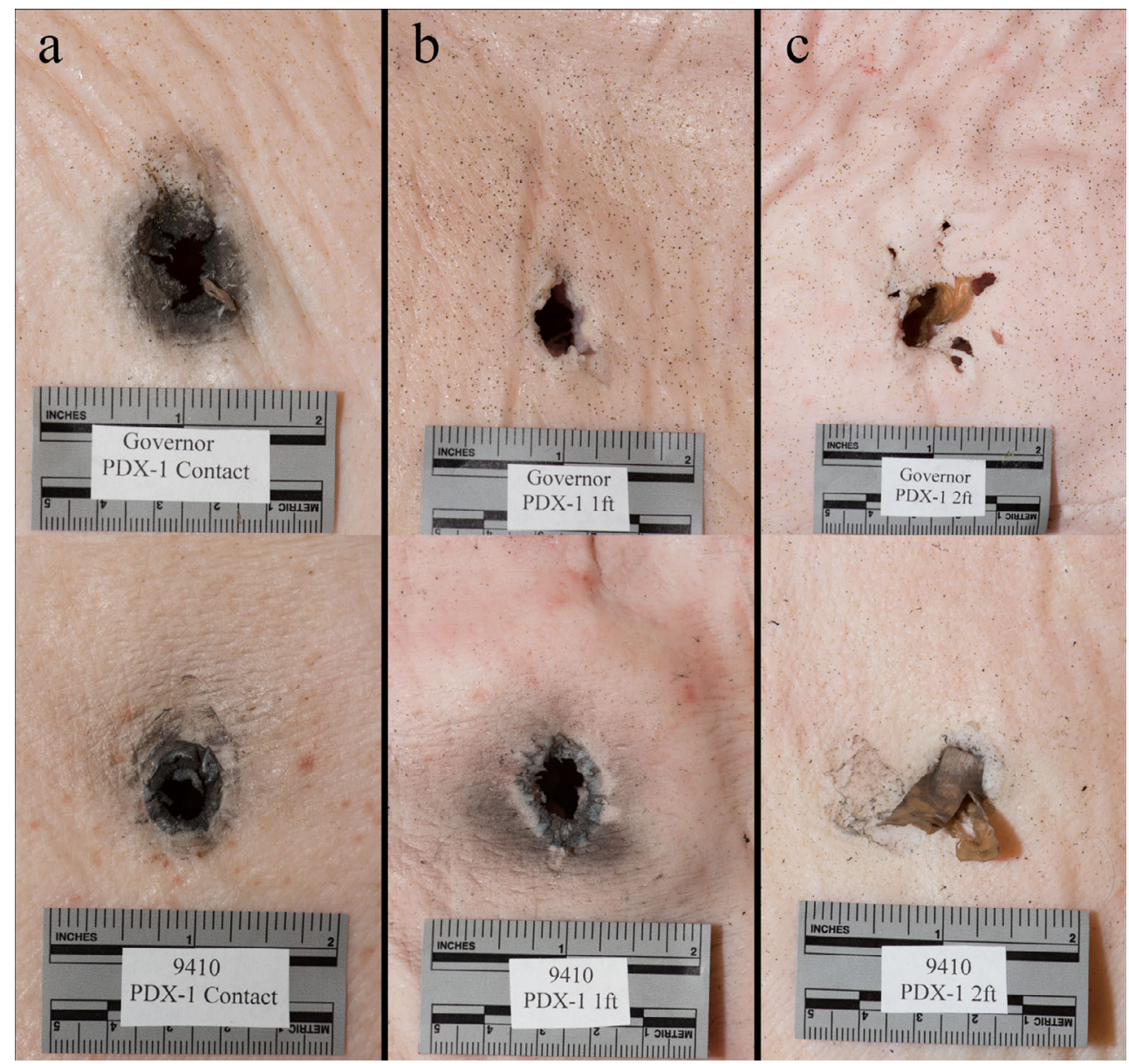

FIG. 3-Entrance wounds fired from the revolver and shotgun at contact, $1 \mathrm{ft}(30.5 \mathrm{~cm})$ and $2 \mathrm{ft}(61 \mathrm{~cm})$ using Winchester ${ }^{\circledR}$ PDXI $^{\circledR} 410$ Defender ${ }^{T M}$. [Color figure can be viewed at wileyonlinelibrary.com] 
skin, with the revolver's being more densely and evenly dispersed.

\section{Three Feet $(91.4 \mathrm{~cm})$}

Figure $4 a$ shows the entrance wounds created at three feet $(91.4 \mathrm{~cm})$. The shotgun created a single defect with imprints from wad strikes and "shot" wipe, which is lubricant, soot, gunpowder, and dirt on a shot's surface. The revolver wound consisted of a larger central defect from the aggregate of discs, wad imprint, and complete dispersion of all $12 \mathrm{BBs}$. As before, both weapons showed gunpowder with the revolver's being more densely and evenly dispersed.

\section{Six Feet $(1.8 \mathrm{~m})$}

Both weapons created wounds at six feet $(1.8 \mathrm{~m})$ (Fig. $4 b)$ with characteristics similar to those at three feet $(91.4 \mathrm{~cm})$, but greater $\mathrm{BB}$ dispersion with the revolver. Additionally, the revolver had unpredictable wad behavior, as it embedded within the wound in two shots but did not strike or enter the skin in three shots. Gunpowder was barely detectable for the shotgun and was finely dispersed for the revolver.
BB pellet dispersion. The revolver wound began to show separation of the defense discs and further separation of the $12 \mathrm{BBs}$ (Fig. 4c). The wad did not enter or strike the skin. Gunpowder was absent for both weapons.

\section{Birdshot Entrance Wounds}

Table 2 displays the average dimensions of the entrance wounds and/or birdshot pellet spread diameters, the presence or absence of gunpowder, and wad or wad imprints from discharging the Remington ${ }^{\circledR}$ American Clay \& Field ${ }^{\mathrm{TM}}$ \#8 birdshot through the Smith \& Wesson ${ }^{\circledR}$ Governor $^{\mathrm{TM}}$ revolver and Winchester ${ }^{\circledR} 9410$ Packer $^{\mathrm{TM}}$ shotgun at contact, $1 \mathrm{ft}(30.5 \mathrm{~cm}), 2 \mathrm{ft}(61 \mathrm{~cm}), 3 \mathrm{ft}(91.4 \mathrm{~cm})$, $6 \mathrm{ft}(1.8 \mathrm{~m}), 9 \mathrm{ft}(2.7 \mathrm{~m}), 15 \mathrm{ft}(4.6 \mathrm{~m})$, and $30 \mathrm{ft}(9.1 \mathrm{~m})$.

\section{Contact}

At contact range, both weapons created lone circular defects, although the revolver entrance wound was three times larger than the shotgun (Fig. 5a). Only wounds created by the shotgun had muzzle abrasions. Both wounds showed soot deposition on the wound edges and surrounding skin, with the revolver wound being fainter than the shotgun.

\section{One Foot $(30.5 \mathrm{~cm})$}

The shotgun wound consisted of a lone circular defect with the wad entering the skin and shot wipe. Faint soot and

At nine feet $(2.7 \mathrm{~m})$, the shotgun wound still maintained the central defect with wad imprint but began displaying minimal

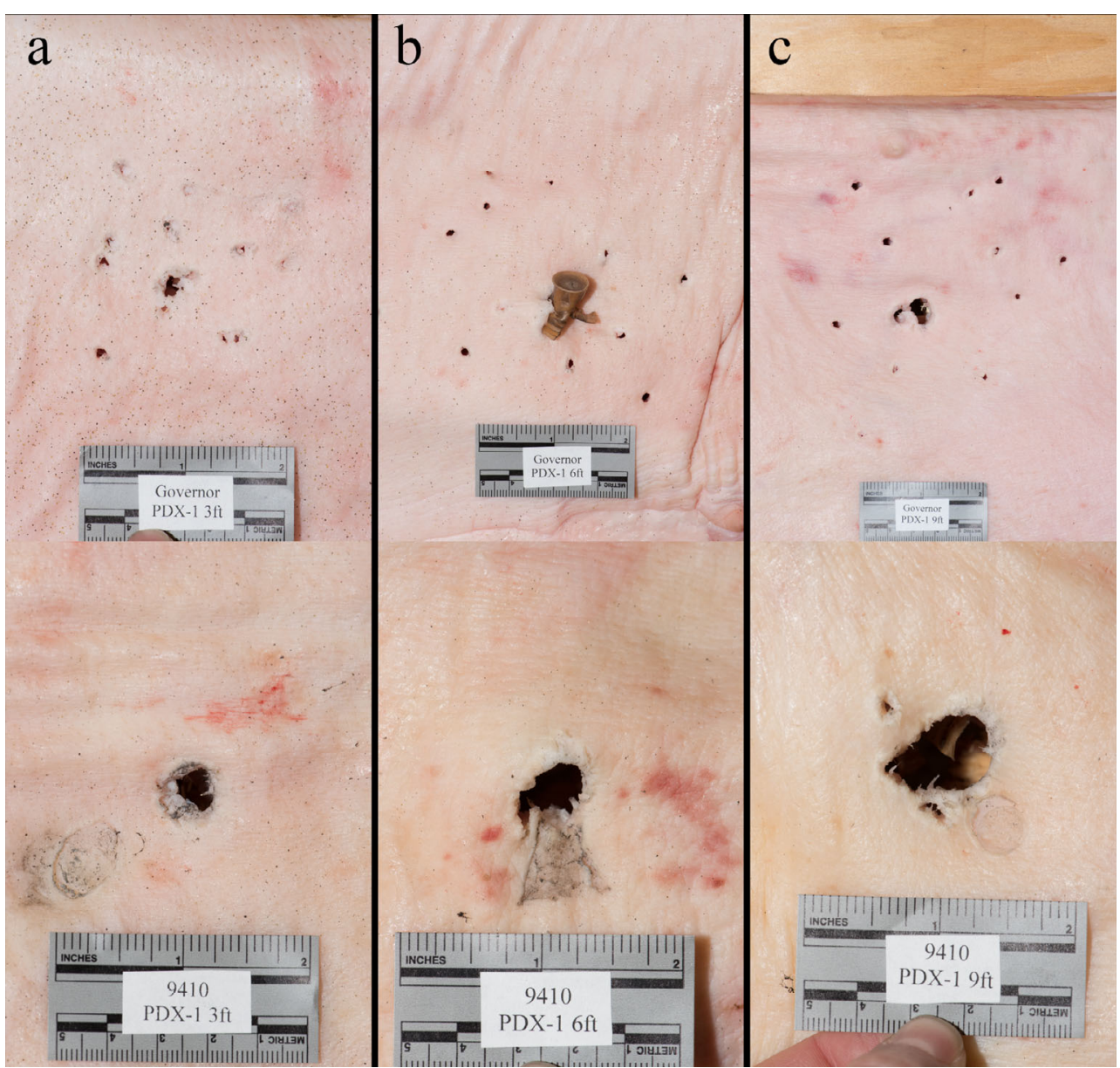

FIG. 4-Entrance wounds fired from the revolver and shotgun at $3 \mathrm{ft}(91.4 \mathrm{~cm}), 6 \mathrm{ft}(1.8 \mathrm{~m})$, and $9 \mathrm{ft}(2.7 \mathrm{~m})$ using Winchester $^{\circledR}$ PDXI $^{\circledR} 410$ Defender ${ }^{\text {TM }}$. [Color figure can be viewed at wileyonlinelibrary.com] 
TABLE 2-Birdshot pellet distribution

\begin{tabular}{|c|c|c|c|c|c|c|}
\hline Weapon & Distance & Pellet Spread Diameter & Wound Appearance & Soot & Gunpowder & Wad or Wad Imprint \\
\hline \multirow[t]{8}{*}{9410 Shotgun } & Contact & $0.3 \mathrm{in} / 0.7 \mathrm{~cm}$ & Muzzle imprint & + & - & - \\
\hline & $1 \mathrm{ft} / 30.5 \mathrm{~cm}$ & $0.6 \mathrm{in} / 1.4 \mathrm{~cm}$ & Single hole & Fine & Fine & + \\
\hline & $2 \mathrm{ft} / 61 \mathrm{~cm}$ & $0.5 \mathrm{in} / 1.3 \mathrm{~cm}$ & Single hole & - & Fine & + \\
\hline & $3 \mathrm{ft} / 91.4 \mathrm{~cm}$ & $0.6 \mathrm{in} / 1.4 \mathrm{~cm}$ & Scalloped edges & - & Fine & + \\
\hline & $6 \mathrm{ft} / 1.8 \mathrm{~m}$ & $1.4 \mathrm{in} / 3.4 \mathrm{~cm}$ & Satellite wounds & - & $+($ few $)$ & + \\
\hline & $9 \mathrm{ft} / 2.7 \mathrm{~m}$ & $3.0 \mathrm{in} / 7.6 \mathrm{~cm}$ & Satellite wounds & - & - & + \\
\hline & $15 \mathrm{ft} / 4.6 \mathrm{~m}$ & $4.6 \mathrm{in} / 11.6 \mathrm{~cm}$ & Dispersed pellets & - & - & + \\
\hline & $30 \mathrm{ft} / 9.1 \mathrm{~m}$ & $12.4 \mathrm{in} / 31.4 \mathrm{~cm}$ & Dispersed pellets & - & - & - \\
\hline \multirow[t]{8}{*}{ Governor Revolver } & Contact & $1.0 \mathrm{in} / 2.6 \mathrm{~cm}$ & Single hole & + & - & - \\
\hline & $1 \mathrm{ft} / 30.5 \mathrm{~cm}$ & $2.0 \mathrm{in} / 5.1 \mathrm{~cm}$ & Satellite wounds & - & Dense & + \\
\hline & $2 \mathrm{ft} / 61 \mathrm{~cm}$ & $3.4 \mathrm{in} / 8.6 \mathrm{~cm}$ & Dispersed pellets & - & Fine & + \\
\hline & $3 \mathrm{ft} / 91.4 \mathrm{~cm}$ & $3.7 \mathrm{in} / 9.4 \mathrm{~cm}$ & Dispersed pellets & - & Fine & - \\
\hline & $6 \mathrm{ft} / 1.8 \mathrm{~m}$ & $7.4 \mathrm{in} / 18.8 \mathrm{~cm}$ & Dispersed pellets & - & $+($ rare $)$ & - \\
\hline & $9 \mathrm{ft} / 2.7 \mathrm{~m}$ & $12.3 \mathrm{in} / 31.1 \mathrm{~cm}$ & Dispersed pellets & - & - & $+($ rosin paper $)$ \\
\hline & $15 \mathrm{ft} / 4.6 \mathrm{~m}$ & $17.6 \mathrm{in} / 44.6 \mathrm{~cm}$ & Dispersed pellets & - & - & $+($ rosin paper $)$ \\
\hline & $30 \mathrm{ft} / 9.1 \mathrm{~m}$ & $27.8 \mathrm{in} / 70.7 \mathrm{~cm}$ & Dispersed pellets & - & - & -(rosin paper) \\
\hline
\end{tabular}

gunpowder were finely and widely dispersed on the skin. The revolver wound had a central defect with the wad entering the skin, but also several smaller satellite defects from spreading birdshot pellets (Fig. 5b). Dense and evenly distributed gunpowder was on the surrounding skin.

\section{Two Feet $(61 \mathrm{~cm})$}

The shotgun wound at two feet $(61 \mathrm{~cm})$ was similar to the wound at 1 foot $(30.5 \mathrm{~cm})$ except that the wad struck but did not enter the skin. With the revolver, the birdshot pellets

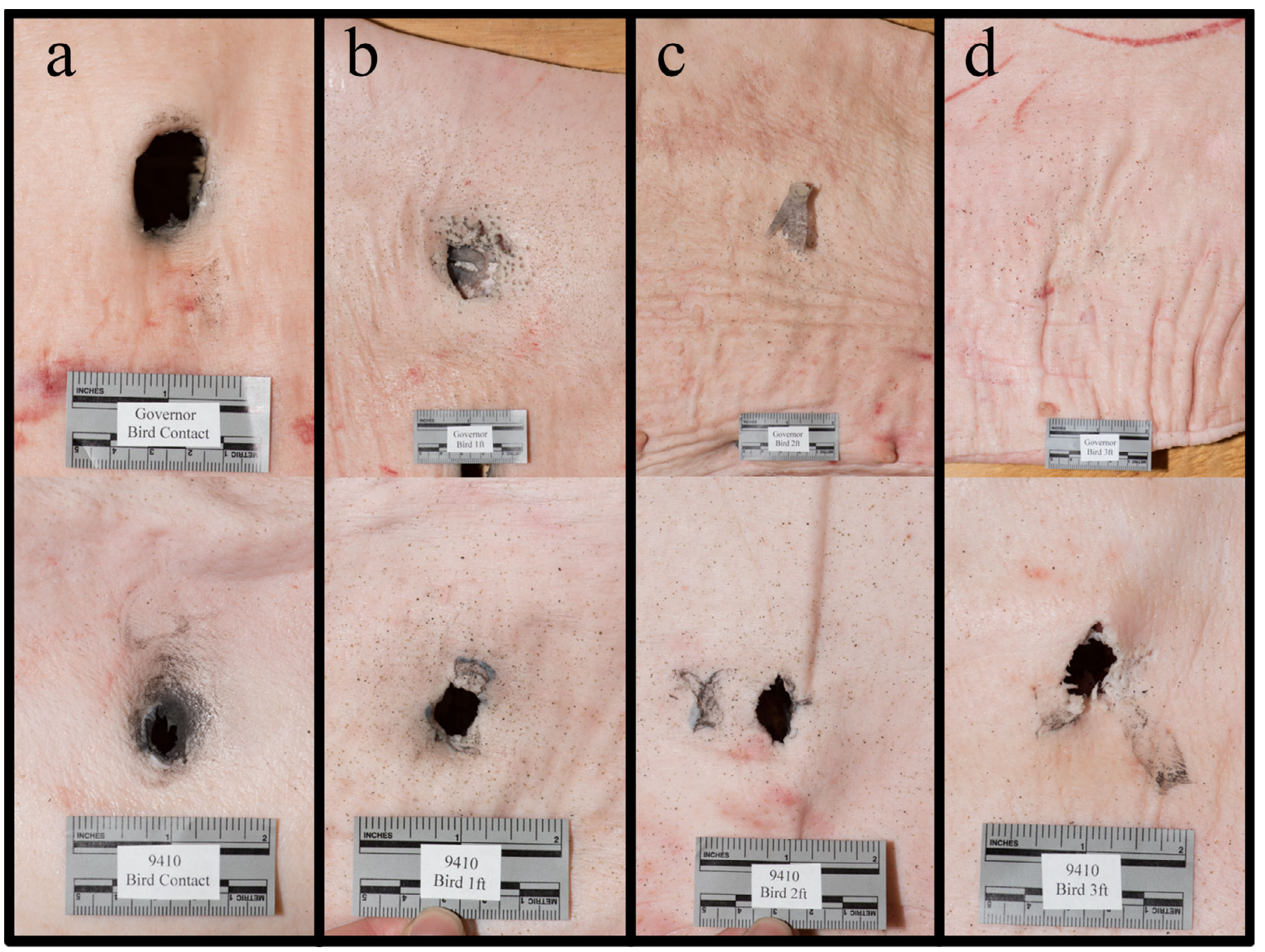

FIG. 5-Entrance wounds fired from the revolver and shotgun at contact, $1 \mathrm{ft}(30.5 \mathrm{~cm}), 2 \mathrm{ft}(61 \mathrm{~cm})$, and $3 \mathrm{ft}(91.4 \mathrm{~cm}) \mathrm{using}$ \#8 birdshot. [Color figure can be viewed at wileyonlinelibrary.com] 


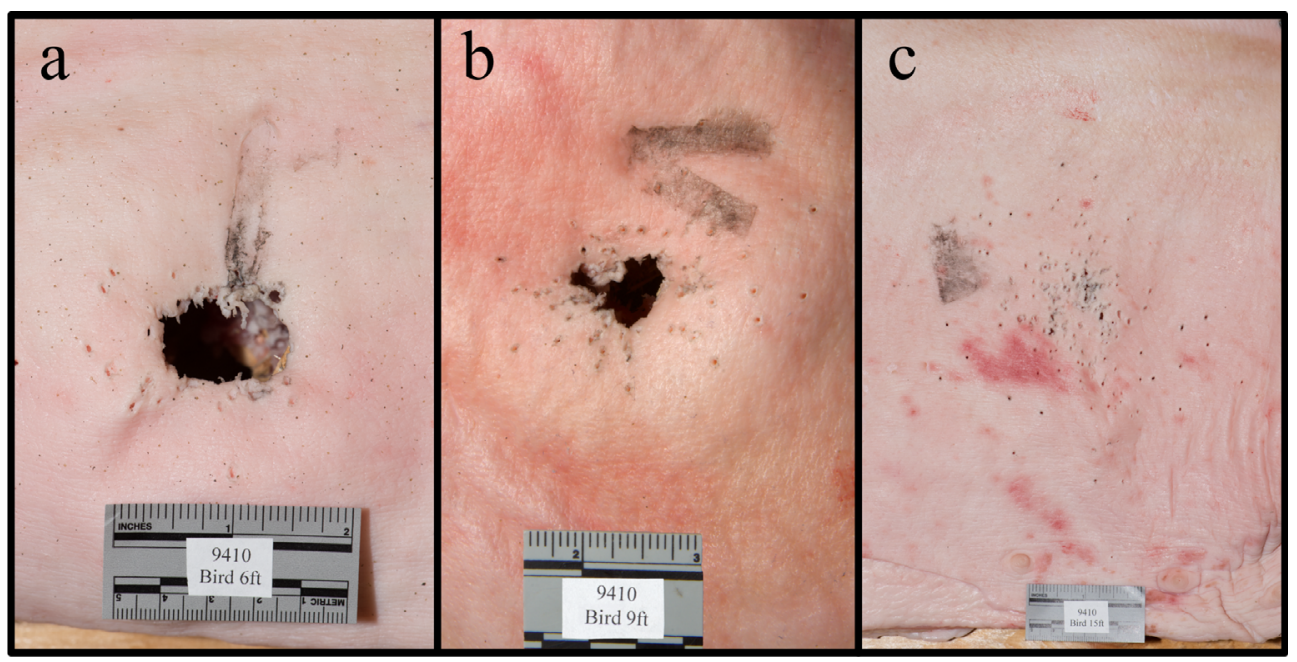

FIG. 6-Entrance wounds fired from the shotgun at $6 \mathrm{ft}(1.8 \mathrm{~m}), 9 \mathrm{ft}(2.7 \mathrm{~m})$, and $15 \mathrm{ft}(4.6 \mathrm{~m})$ using \#8 birdshot. [Color figure can be viewed at wileyon linelibrary.com]

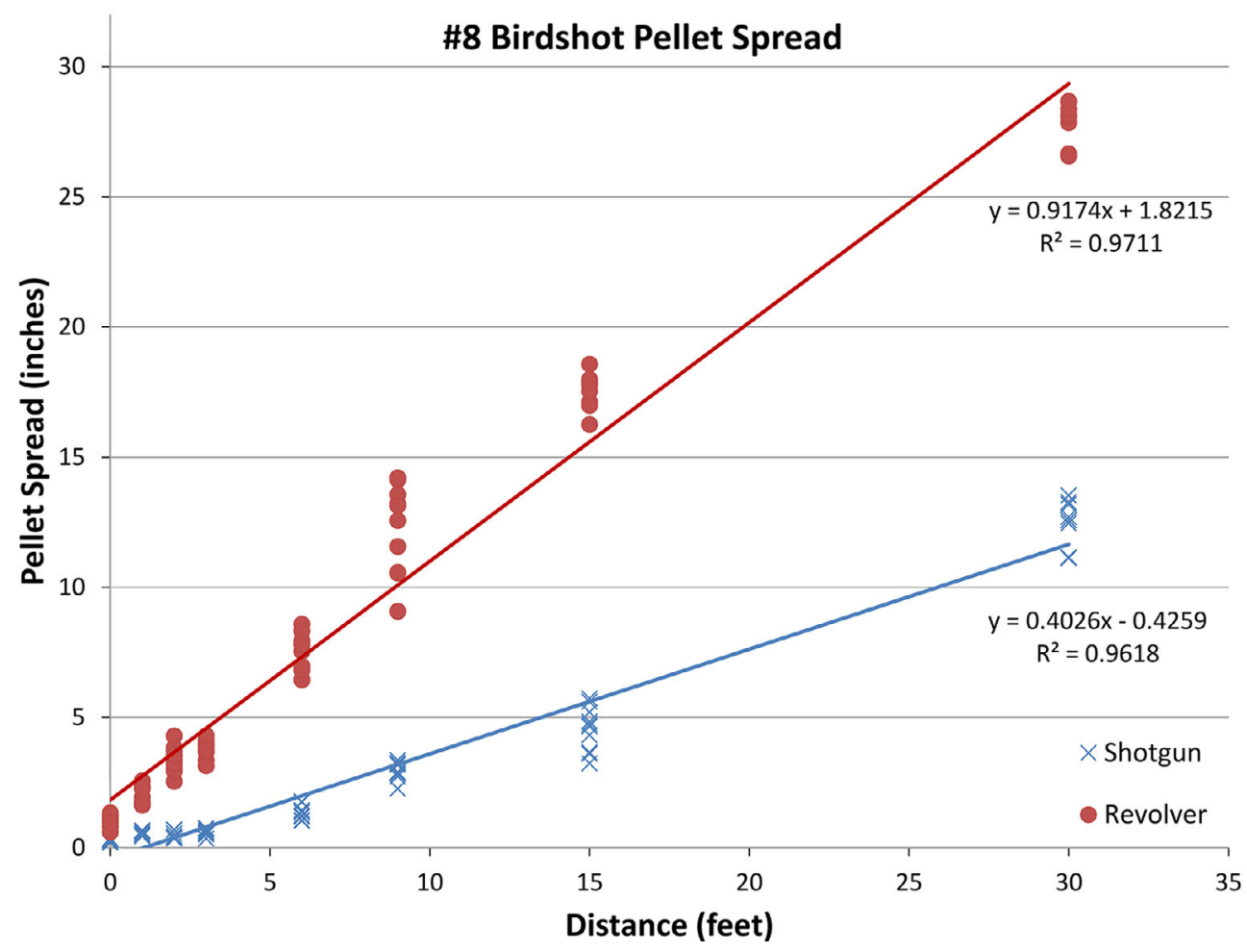

FIG. 7-Plot of revolver and shotgun pellet spread using \#8 birdshot. [Color figure can be viewed at wileyonlinelibrary.com]

completely separated prior to striking the skin and the wad either imprinted but did not enter the skin or did not strike the skin (Fig. 5c). Fainted and widely dispersed gunpowder were on the skin surrounding both wounds.

\section{Three Feet $(91.4 \mathrm{~cm})$}

Scalloped edges were apparent with the shotgun wound fired from three feet $(91.4 \mathrm{~cm})$, as were wad imprints (Fig. $5 d$ ). The revolver wound displayed further separation of the birdshot and no wad strike impressions. Gunpowder was on the skin surrounding both wounds.

\section{Six Feet $(1.8 \mathrm{~m})$}

In extending the distance to six feet $(1.8 \mathrm{~m})$, satellite pellet wounds became apparent with the shotgun. Visible wad imprints were still present (Fig. 6a). The revolver wounds had a wide pellet spread with no wad imprints. A few grains of gunpowder were on the skin of the shotgun wound, while the revolver had 
widely dispersed gunpowder grains were deposited with the revolver.

Nine Feet $(2.7 \mathrm{~m}), 15$ Feet $(4.6 \mathrm{~m})$, and 30 Feet $(9.1 \mathrm{~m})$

The entrance wound created by the shotgun fired at nine feet $(2.7 \mathrm{~m})$ (Fig. 6b) had a ragged central defect with scalloped wound edges and increased satellite pellet wounds. At 15 feet $(4.6 \mathrm{~m})$ (Fig. 6c), the shotgun wound consisted of only dispersed pellet wounds and a wad impact. The pellets spread increased further at 30 feet $(9.1 \mathrm{~m})$. Wad imprints were present at nine feet $(2.7 \mathrm{~m})$ and 15 feet $(4.6 \mathrm{~m})$, and no wad strikes were seen at 30 feet $(9.1 \mathrm{~m})$ when using the shotgun. With the revolver, wad strikes were identified on the rosin paper at nine feet $(2.7 \mathrm{~m})$ and 15 feet $(4.6 \mathrm{~m})$, but not at 30 feet $(9.1 \mathrm{~m})$.

Both weapons had a direct and predictable relationship between pellet spread and the distances studied. In comparing entrance wound diameters and/or birdshot pellet spread diameters to the muzzle-to-target distances, linear curve fit equations had coefficient of determination $\left(r^{2}\right)$ values of 0.97 and 0.96 for the shotgun and the revolver, respectively (Fig. 7).

\section{Entrance Wounds from .410 Slug and Similar-Caliber Bullets}

The .410 Foster slugs (regardless of weapon), .40 S\&W HP bullet, $10 \mathrm{~mm}$ HP bullet, and .45 ACP HP bullet created

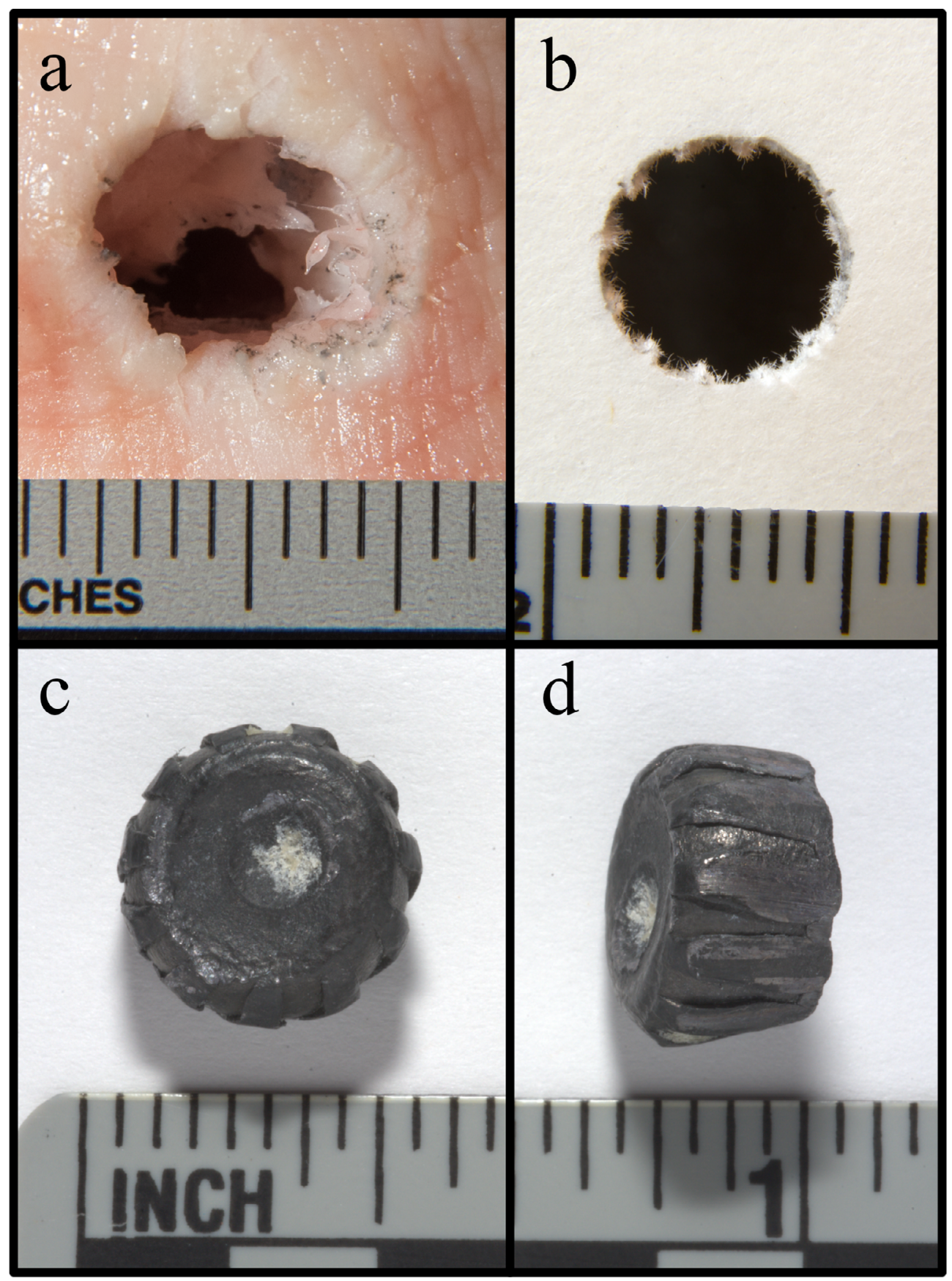

FIG. 8-.410 bore slug entrance wound morphology. (a) skin. (b) cardstock. (c) top view of fired slug. (d) side view of fired slug. [Color figure can be viewed at wileyonlinelibrary.com] 
perforations with roughly similar diameters. While present on all wound edges, soot, dirt, and lubricant were most prominent on the $10 \mathrm{~mm} \mathrm{HP}$ and the .410 slug revolver wounds. On close scrutiny, the Foster slug's vanes/fins imparted undulating peaks and valleys along the wound margins. A more demonstrative illustration of these oscillations was created when a slug was fired through cardstock (Fig. 8).

\section{Discussion}

The .410 shotshell creates difficulties for the certification and investigation of a firearm death as it can be fired through a .410 smooth bore shotgun and certain rifled-barrel handguns. The differences in the cutaneous wounds from the Winchester ${ }^{\circledR}$ PDX $1^{\circledR}$ 410 Defender $^{\mathrm{TM}}$ shotshells fired from these two types of weapons have not been previously studied. This study examined the differences in the cutaneous wounds created by PDX $1^{\circledR} .410$ shotshells and standard \#8 birdshot fired from these weapons at predetermined distances from porcine skin.

Both ammunition types used in this study demonstrated a consistent contrast between the shotgun and the revolver. The rate of disc and pellet separation was greater with the revolver than the shotgun at all distances beyond contact range with both ammunition types. When loaded with PDX $1^{\circledR} .410$ shotshells, the revolver displayed complete separation of the BB pellets at 3 feet $(91.4 \mathrm{~cm})$ while the shotgun only began to show separation at nine feet $(2.7 \mathrm{~m})$. Similarly, when shooting the Remington ${ }^{\circledR}$ American Clay \& Field $^{\mathrm{TM}}$ \#8 birdshot, complete birdshot separation was observed at 2 feet $(61 \mathrm{~cm})$ with the revolver, but was not achieved from the shotgun until 15 feet $(4.6 \mathrm{~m})$.

The findings were not as dichotomous when comparing the presence of soot and gunpowder from the two weapons using either ammunition. While present for both weapons, there was generally a higher density and increased ease of detection of gunpowder on the skin with the revolver discharging either the PDX $1{ }^{\circledR} .410$ shotshells or the \#8 birdshot. In contrast, soot was largely present at farther distances with the shotgun firing either ammunition. Mirroring this, the wad from either ammunition fired from the shotgun reliably entered the skin, became imbedded within the skin, or struck the skin at distances greater than the revolver. These differences reflect the more complete combustion of gunpowder as it travels through the longer barrel of the shotgun. This combustion increases the ratio of soot to gunpowder and the velocity and distance traveled by the wad.

When attention is turned to injuries created by the .410 bore slug, measurements of the cutaneous wounds provide no useful information in separating it from common handgun calibers (.40 $\mathrm{S} \& \mathrm{~W}, 10 \mathrm{~mm}$, and $.45 \mathrm{ACP})$. Scrutinizing the wound margins may identify peaks and valleys imparted by the characteristic vanes of the Foster slug. While this can help guide a medicolegal death investigation, it does not differentiate whether the slug was fired from a shotgun or handgun.

In conclusion, when examining wounds created by the Winchester ${ }^{\circledR}$ PDX $1{ }^{\circledR} 410$ Defender $^{\mathrm{TM}}$ shotshell, at distances from 1 foot $(30.5 \mathrm{~cm})$ or less, definitive distinction between wounds created by the Winchester ${ }^{\circledR} 9410$ Packer $^{\mathrm{TM}}$ shotgun and gunshot wounds from the Smith \& Wesson ${ }^{\circledR}$ Governor $^{\mathrm{TM}}$ revolver cannot be made. In this study, the presence of gunpowder in conjunction with a wide BB pellet spread was seen using the Smith \& Wesson ${ }^{\circledR}$ Governor ${ }^{\mathrm{TM}}$ revolver. Similarly, with Remington ${ }^{\circledR}$ American Clay \& Field ${ }^{\mathrm{TM}} \# 8$ birdshot, contact range discharge through the shotgun could not be distinguished from the revolver and wide birdshot pellet spread combined with detectable gunpowder was experienced with firing using the Smith \& Wesson ${ }^{\circledR}$ Governor $^{\mathrm{TM}}$. The differences in wound size and shape, injuries from the wad, and soot and gunpowder on the skin indicate that estimations of the range of fire should only be made with great caution if information about the type of weapon creating the injury (s) is not provided to the forensic pathologist.

\section{References}

1. DiMaio VJM. Gunshot wounds: practical aspects of firearms, ballistics, and forensic techniques. Boca Raton, FL: CRC Press, 2016;179-224.

2. Poulos C. A review of newly developed firearms that can fire multiple ammunition types. Acad Forensic Pathol 2013;3(2):139-43.

3. DeBeer S, Le Luduec JB, Kaiserlain D, Laurent P, Nicolas JF, Dubois B, et al. Comparative histology and immunohistochemistry of porcine versus human skin. Eur J Dermatol 2013;23(4):456-66.

4. Haag M, Haag L. Skin perforation and skin stimulants. AFTE J 2002;34 (3):268-86.

5. Poulos C, Tiomak W. A review of new projectile types. Acad Forensic Pathol 2013;3(2):144-53. 